\title{
Knowledge Management Strategies and Innovation. An application to artisanal SMEs in Morocco
}

\author{
Fadoua Ktiri ${ }^{1}$, Mustapha Bachiri ${ }^{2}$, Souad Guelzim ${ }^{3}$. \\ ${ }^{1}$ Laboratory: Prospective studies, strategy and organizations development, Ibn Tofail University, Kenitra, \\ Morocco. \\ ${ }^{2}$ Mohamed V University - Rabat, Morocco. \\ ${ }^{3}$ Laboratory: Prospective studies, strategy and organizations development, Ibn Tofail University, Kenitra, \\ Morocco.
}

\begin{abstract}
This paper provides empirical support for the literature on knowledge management and innovation. It aims to measure the impact of codification and personalization strategies as well as the impact of the type of internal or external knowledge on innovation. The empirico-deductive study concerns 32 Moroccan artisanal SMEs operating in six artisanal businesses including leather, pottery, carpentry, traditional textile, bakery / pastry and butchery. The results of the study show that internal knowledge and codification strategy improve innovation behavior, while the personalization strategy and external knowledge do not affect innovation. Building on these findings, the article proposes to help researchers and managers reinvent knowledge management within their companies to trigger more innovation.
\end{abstract}

Keywords: artisanal SMEs, External knowledge, Innovations, Internal knowledge, Knowledge Codification, Knowledge personalization.

\section{Introduction}

In recent decades, companies are faced with major changes induced mainly by accelerated diffusion of new technologies, shorter product lifecycles and increased competition. These changes impose maximization of value for the costumer and the stakeholders and lead firms to reinvent themselves perpetually by innovation. According to Teece [57], the survival of firms in changing environments depends on their ability to manage change by the combination and the reconfiguration of the assets that can be mobilized inside and outside the company.

From then on, innovation becomes an indisputable requirement in an economy gradually transformed into a knowledge society. Competitiveness requires companies to develop their ability to produce, transfer, use and protect knowledge assets that are hard to imitate [56]. Knowledge-based firm theory considers it as a strategic resource as important as financial, human or technical capital. In this context, the large industrial enterprise does not have the monopoly of innovation, Small and medium-sized enterprises (SMEs) in general, artisanal SMEs in particular, have a potential for innovation in view of its flexibility, proximity to the costumer and the importance of his tacit knowledge.

Innovation is today an imperative for competitiveness and sustainability for the artisanal companies, despite the nature of its activity, which refers more to stability, to the intergenerational transmission of ancestral gestures and to the preservation of culture than to innovation. After being hidden for a long time from studies on innovation and presented as a sector in decline, Boldrini believes that artisanal companies has become, today, an important object of observation [8]. This renewed interest in the problem of innovation in the artisanal environment was triggered by the $\mathrm{TIME}^{1}$ survey, which revealed a real potential for innovation in this sector.

On the other hand, artisanal companies has been able to withstand the turbulence of the environment and the competition of the mass industry, mainly because of its ability to maximize value to the customer through personalized products and respondents. However, the majority of studies have long limited themselves to measuring the technological innovations of large enterprises through the number of patents filed, and expenditure on research and development, dedicated to research and development, and the number of patented [7]. These indicators are not adapted to artisanal companies where innovation is not necessarily of a technological nature or originates from research and development laboratories but rather is induced by its internal knowledge (tacit and explicit knowledge) and its absorptive capacity [16]. This reflects the company's ability to acquire and exploit external knowledge through contractual market arrangements and a permanent

1 TIME (technology and innovation in craft enterprises): a qualitative survey carried out in 1997 and renewed in 2002 at the request of the Institut Supérieur des Métiers, with the assistance of INSEE in 1,000 craft production companies 
environmental monitoring system. Knowledge as both input and output of innovation is crucial especially for the artisanal enterprise given its specific characteristics (strong cultural anchorage, family-oriented enterprise, low rate of supervision and limited financial resources) which do not allow it to adopt new management practices or innovation management tools that optimize knowledge management processes for innovation.

The purpose of this article is to question the basis of the relationship between knowledge management strategies and types of innovation in artisanal enterprises. Through this work, it seems necessary to refine the understanding of the interactions between the phenomena studied and the practices that are inherent to it.

The paper first presents a theoretical framework of the knowledge management phenomenon and innovation, followed by materials and methods of research. The results of the research and the discussions will then be developed, leading to a conclusion that evokes the theoretical and managerial implications of this study and its main limitations.

\section{Theoretical Frame}

Knowledge management practices have long existed as a practice of internal (meetings, training, mentoring, etc.) and external knowledge exchange (market studies, partnership, subcontracting ...). But the term "Knowledge Management" only dates back to 1989, with an article published in the Harvard Business Review triggering the first scientific writings on this topic, notably the founding works of Drucker [20] and Nonaka and Takeuchi [49].

However, defining Knowledge Management, despite the abundance of writings [29], does not seem easy because of the multiplicity of epistemological and ontological aspects of the concept of knowledge itself. López-Nicolás and Meroño-Cerdán [39] define knowledge management as "a set of explicit and systematic processes for the creation, organization, dissemination, use and exploitation of corporate knowledge". Coombs and al. [17] also add "process of identifying, capturing, modifying, validating, contextualizing and closing knowledge to enrich the traditional view of knowledge management". The list of processes is obviously not exhaustive. They can be classified into three broad categories: creation, application and appropriation of knowledge [2].

Each knowledge management process is very important in the innovation management. By referring to Herkema,

innovation can be defined as a process in which knowledge is acquired, shared and assimilated in order to create new knowledge through products and services [33].

The first work on innovation is attributed to Schumpeter [53], he identifies five types of innovations:

1) Product innovation, which may be radical if it generates entirely new products, or incremental, if it involves the improvement of existing categories;

2) Process innovation that involves the introduction of new production;

3) Opening up new markets;

4) Development of new sources of supply (raw, semi-finished or finished materials);

5) Development of a new organization in an industry.

These types have been taken up and complemented by the OECD manual [50] incorporating marketing innovation more targeted the service activities. Gloet and Terziovski [26] distinguish radical and incremental innovation. Incremental innovations are presented as extensions or line modifications of existing products. They are generally classified as market-pull innovations. Incremental innovation does not require a large gap in existing knowledge and business practices and therefore offers the possibility of building on already existing internal know-how. Radical innovations are likely to destroy existing knowledge, which often makes existing skills obsolete and require different management practices, which can expose the company to risks despite their importance in the long run. Today, the literature proposes an integrated vision of the knowledge management and innovation. The knowledge management and the innovation management have long been regarded as two separate literatures [4], because "they have been produced by different scientific communities, using methods and theories that are sometimes opposed" [18]. Knowledge has been taken into account in innovation only in an underlying way [18]. The interaction between innovation and knowledge has become direct only since the work of Cohen and Levinthal [16], which focused on absorptive capacity, which is defined as the ability to recognize, assimilate and apply knowledge from the environment for commercial purposes.Today, "knowledge and innovation are inseparable" [21]. Interactive approaches to innovation and knowledge have occupied several thematic issues. We quote West et al. [58] in Industrial Economics Review whose theme was "Open innovation", Attour and Helmchen [3] To the Industrial Economics Journal. Robins [52] to the thematic issue of the magazine Long Range Planning focused on business models, Fréry et al. [24] to The French management magazine, Bensbaa and Beraud [5] to the Journal of Economics and Innovation Management, and the various thematic issues on business ecosystems published by Management \& Avenir Gratacap [27]. In all these works, knowledge and learning are considered to be crucial in the process of innovation. 
It should also be noted that while the existing literature agrees on the positive impact of knowledge management on innovation, this impact differs according to the types of knowledge used and the knowledge management strategies adopted. Knowledge management strategy refers to the processes and infrastructure that the company employs to acquire, create and share knowledge for strategy formulation and strategic decision making [15]. Understanding of knowledge management strategies can be refined by reviewing the most important contributions from the literature below (Table 1).

Table 1: Synthesis of Knowledge Management Strategies

\begin{tabular}{ccc}
\hline Authors & Systèm-oriented & Humain-oriented \\
\hline Hansen et al. [32] & Codification & Personnalisation \\
March [42] & Exploitation & Exploration \\
Bierly and Charabarti [6] & Exploiters & Innovators, Explorers \\
Jordan and Jones [36] & Explicit-oriented & Tacit-orientede \\
Zack [60] & Conservative & Aggressive \\
Choi and Lee [14] & Systems-oriented & Dynamic, human-oriented \\
Garavelli et al. [25] & Market & Community \\
Martini and Pellegrini [43] & Codification & Network-based; Traditional \\
Mom et al. [45] & Exploitation & Exploration \\
Moitra and Kumar [44] & - & Socialisation \\
Wu and Lin [59] & Copier, continuous & Conquest of competence \\
& improver & innovator \\
\hline
\end{tabular}

Source : adapted from López-Nicolás and Meroño-Cerdán, [39].

The approach of Hansen et al. [32] on codification and personalization, proposes the distinction between tacit knowledge and explicit knowledge. In the codification strategy, knowledge is extracted from the people who developed it, then it is made independent of the person and reused for various purposes [39]. This strategy relies mainly on documents, repositories and databases to make knowledge explicit. The personalization strategy is based on tacit knowledge and focuses on the different forms of dialogue and exchange between people (Table 2).

Table 2: Knowledge management strategies: codification and personalization

\begin{tabular}{ccc}
\hline & Codification & Personnalisation \\
\hline Knowledge managed & Knowledge reuse & New solutions and \\
Focus & Explicit & knowledge development \\
Use of IT & Person-to-documents & Person-to-person \\
& $\begin{array}{c}\text { Heavy IT investment : connecting people } \\
\text { and reusable knowledge }\end{array}$ & $\begin{array}{c}\text { Moderate IT investment : } \\
\text { facilitating dialogue and tacit } \\
\text { knowledge sharing }\end{array}$ \\
Main tools & Decision support systems & Mentoring Groups \\
& Document repositories & Videoconferencing \\
& Knowledge maps & Bellow pages E-mail \\
& Workflow Best practices & Discussion forum \\
databases & Mentoring Rewarding \\
Human resource & E-learning & knowledge sharing \\
management & Rewarding the use & with others \\
& of and contribution to databases & Knowledge cataloguing is easy \\
Advantages & Economies of scale & Flexible and adaptable \\
& Time savings & knowledge \\
& No need of & Improvements in \\
& task quality \\
& reinventing the wheel & Management of \\
& Quicker and wider access & And distribution of \\
knowledge & Improvements in clients image \\
& High cost & uncodificable knowledge \\
& Codified knowledge & Unwillingness to share \\
& Loses richness & Inappropriate culture \\
& & \\
\hline
\end{tabular}

Source: Adapted from Hansen et al.[32], Alvesson and Karreman [1],

Hansen and Haas [31], Flanagin [22], Inuzuka and Nakamori [34]. There is a close link between the company knowledge and its ability to innovate and create [10]. According to Lopez-Nicolas and Merono-Cerdan [39], both codification and personalization can improve business innovation. Swan and al. [55] indicate that it is mainly exploration and knowledge sharing that allow for the development of innovation because it emphasizes tacit knowledge, while Majchrzak et al. [40] propose a positive impact of the re-use of explicit knowledge on 
which the codification strategy is based. According to the theory of Nonaka and Takeuchi [49], there are two types of knowledge: explicit and tacit. Tacit knowledge can be defined as disarticulated knowledge rooted in experience. It concerns unwritten know-how that is resides in the heads of employees [49]. Explicit knowledge is defined as a knowledge that can be formulated in sentences [48] It is easily codified and transferable by information systems as it is captured and shared [49].

In this context, Majchrzak et al. [40] propose a positive impact of the re-use of explicit knowledge on innovation. Swan et al. [55] place more emphasis on tacit knowledge and consider that innovations can be developed, in large part, through the exploration and sharing of tacit knowledge. Indeed, tacit know-how that cannot be codified can represent nearly two-thirds of firms' 'knowledge capital' [35]. This is all the more true for artisanal enterprises, where inter-individual, informal and direct communication are the main processes for the acquisition, transmission and dissemination of tacit knowledge [19].

Another approach has focused on the origin of knowledge (internal or external). It contributes to understanding the impact of knowledge on the types of innovations. According to Smith et al. [54], firms can generate and accumulate new knowledge by following two different but complementary paths :

- The first way, through a process of knowledge creation that builds on employees' internal skills and experiences [54]. Forés and Camisón [23] add that the company is capable to develop radical innovations when its knowledge is based on research and development;

- The second way is to acquire new knowledge from external sources by developing their absorptive capacity [16].

According to Bierly and Chakrabarti [6], the internal creation of knowledge occurs when the members of the organization generate, transfer and integrate new knowledge within the internal boundaries of the firm. This ability to create internal knowledge allows to add new components to the company's knowledge base through organization, creativity, experience, learning, experimentation, R\&D and problem solving $[9 ; 47 ; 54]$.

Lema et al. [38] confirm that "a fundamental change has occurred in the way innovation is organized. It is now more decentralized within the company. Innovation activities, formerly carried out internally by innovative firms, are also carried by independent service providers or are transferred to key suppliers". Increased competitive pressure has led companies to decompartmentalize their R\&D and innovation activities, deploying strategies that rely increasingly on combining their internal capacities with a variety of external resources [38]. This innovation management takes the form of business ecosystems or clusters.

\section{Conceptual model}

\section{Materials And Methods}

Our conceptual model (Figure 1) links knowledge management strategies (as independent variables) to innovation (as a dependent variable). Independent variables are measured by four dimensions: personalization, codification, internal knowledge and external knowledge. It involves an analysis oriented towards knowledge management strategies. The main research question that this contribution seeks to address is the impact of the knowledge management strategy on the ability to develop innovations to create more value for the client and for stakeholders.

To analyze the knowledge management strategy, this research focuses on two types of work, those of Hansen et al. [32] on strategies for codification and personalizing knowledge, and those dealing with the impact of knowledge sources (internal or external) on innovation, namely Bierly and Chakrabarti [6], Smith et al. [54], Forés and Camisón [23].

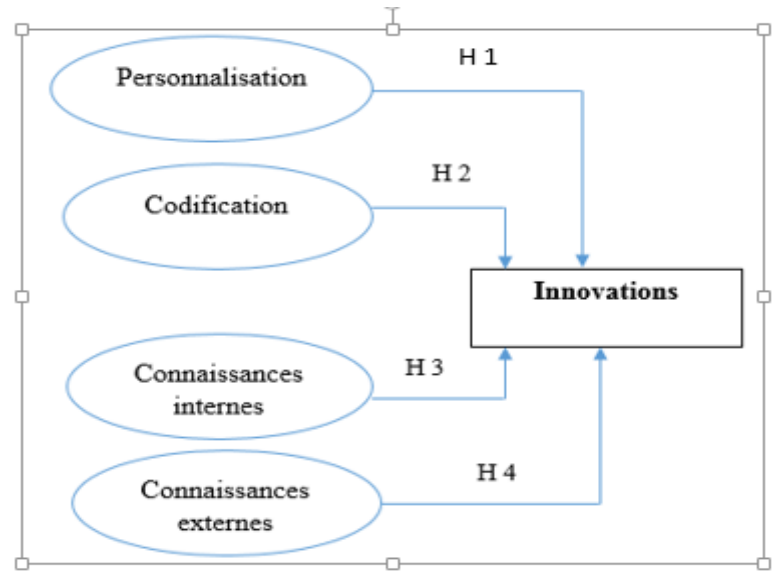

Figure 1: Conceptual model 
The model variables are measured using a multicriteria scale. Codification and personalization are measured by 7 items, referring to the work of Choi and Lee [13; 14], including 4 items for personalization and 3 items for codification. The internal knowledge and external knowledge dimensions are measured by 6 items, 3 items relate to internal knowledge and 3 items to measure external knowledge, Referring to the work of Bierly and Chakrabarti [6]; Smith et al. [54]; Forés and Camisón [23]. (Table 3).

As for the innovation variable, we opted for the typology of Mortensen and Bloch [46] of the Oslo manual. 4 types of innovation are considered in our model:

- Product innovation: new products or services (radical innovation) or improved products (incremental innovation);

- $\quad$ Process innovation: new or improved method of production or distribution;

- $\quad$ Marketing innovation: new marketing methods (packaging, promotion, pricing, placement);

- Organizational innovation: new method in the practices, new organization of the workplace or the external relations of the firm.

Table 3: Knowledge management strategies measurement items

\begin{tabular}{|c|c|c|c|}
\hline \multicolumn{2}{|c|}{ Variables } & Items & Authors \\
\hline \multirow{2}{*}{ Codification } & SKM1 & $\begin{array}{l}\text { Knowledge (know-how, technical skills and problem solving } \\
\text { methods) are well codified in your company }\end{array}$ & \multirow{2}{*}{$\begin{array}{l}\text { Hansen et al. [32] } \\
\text { Choi and lee [14] }\end{array}$} \\
\hline & SKM2 & $\begin{array}{l}\text { Knowledge sharing takes place through codified forms such as } \\
\text { manuals and documents in your company. }\end{array}$ & \\
\hline \multirow[t]{2}{*}{ Personalization } & SKM5 & $\begin{array}{l}\text { Knowledge can be easily acquired from experts and coworkers } \\
\text { in your business. }\end{array}$ & \multirow{2}{*}{$\begin{array}{l}\text { Hansen et al. [32] } \\
\text { Choi and Lee [14] }\end{array}$} \\
\hline & SKM6 & It is easy to take advice directly from experts in your business & \\
\hline \multirow{3}{*}{ Internal knowledge } & Cint1 & $\begin{array}{l}\text { New knowledge is created internally by the skills of employees } \\
\text { in your company. }\end{array}$ & Bierly and Chakrabarti [6] \\
\hline & Cint2 & $\begin{array}{l}\text { Your company is able to develop innovations through internal } \\
\text { research and development }\end{array}$ & Smith et al. [54] \\
\hline & Cint3 & $\begin{array}{l}\text { Training is scheduled for employees to acquire new knowledge } \\
\text { in your company }\end{array}$ & Forés and Camisón [23] \\
\hline \multirow{3}{*}{$\begin{array}{c}\text { External } \\
\text { knowledge }\end{array}$} & Cext 1 & $\begin{array}{l}\text { Your company acquires new external knowledge from its } \\
\text { customers, partners and competitors through its absorption } \\
\text { capacity }\end{array}$ & $\begin{array}{l}\text { Cohen and Levinthal [16]; } \\
\text { Lema et al. [38] }\end{array}$ \\
\hline & Cext2 & $\begin{array}{l}\text { Can employees screen out the useful KM for the firm from } \\
\text { external environment? }\end{array}$ & Maltz et al. [41] \\
\hline & Cext3 & $\begin{array}{l}\text { Can employees communicate the knowledge obtaining from } \\
\text { external environment with their managers? }\end{array}$ & Gray and Meister [28] \\
\hline
\end{tabular}

\section{Model hypotheses:}

The theoretical framework mobilized in this study led us to formulate the following hypotheses:

\section{- H1. The knowledge codification improves innovation;}

- H2. The knowledge personalization improves innovation;

- H3. Internal knowledge is a source of innovation;

- H4. External knowledge is a source of innovation;

\section{Research methodology:}

The conceptual model presented in Figure 1 has been empirically tested. Our research emphasizes an empirico-inductive exploratory approach. The answers were collected by closed-ended questionnaire with Likert scale from 1 to 5 with 1: strongly disagree and 5: strongly agree. The questionnaire was administered in three ways: the direct contact of the interviewees, the telephone interview and the e-mailing. The questionnaires sent by emailing were preceded by a letter explaining the framework of the research and its objectives. One of the major difficulties in carrying out this study remains the possibility of obtaining the approval of the respondent to join the survey. This situation can be explained mainly by the predominance of family management in the artisanal enterprise and its dominant culture.

The sample is made up of 32 small and medium-sized artisanal enterprises (SMEs) located in Rabat, morocco's capital known for its high concentration of cultural crafts. These companies represent six artisanal activities: pottery, carpets, butchers, bakery/Pastry, textiles and carpentry. The characteristics of respondents and the profile of respondents are presented in Table 4. 
Table 4: Description of sample

\begin{tabular}{|l|c|}
\hline & \% of sample \\
\hline Number of employees (NE) & 37,5 \\
$\mathbf{1 0}<\mathbf{N E}<\mathbf{5 0}$ & 25 \\
$\mathbf{5 0}<\mathbf{N E}<\mathbf{1 0 0}$ & 18,75 \\
$\mathbf{1 0 0}<\mathbf{N E}<\mathbf{1 5 0}$ & 18,75 \\
$\mathbf{1 5 0}<\mathbf{N E}<\mathbf{2 5 0}$ & \\
business sector & 16,66 \\
Pottery & 16,66 \\
Carpets & 16,66 \\
Joinery (wood craft) & 16,66 \\
Traditional textile & 16,66 \\
Bakery pastry & 16,66 \\
Butchery & \\
Profile of the respondent & 10 \\
Founding Craftsman & 30 \\
General manager & 30 \\
Workshop chief & 30 \\
Experienced craftsman & \\
Geographical location & 68,75 \\
One localization & 31,25 \\
More than one location & \\
\hline
\end{tabular}

The data processing was carried out by the SPSS software. The model presents five variables that we have tried to explain through several items measured by 5 -point scales.

Table 5: Measurement structure of the variable

\begin{tabular}{|l|c|c|}
\hline & Variable & Number of items \\
\hline \multirow{3}{*}{ ependent variable } & Innovation & 5 items \\
\hline \multirow{3}{*}{ ndependent variables } & Internal Knowledge & 3 items \\
& External Knowledge & 3 items \\
\cline { 2 - 3 } & Codification & 2 items \\
\cline { 2 - 3 } & Personalization & 2 items \\
\hline
\end{tabular}

In order to verify the applicability of our explanatory model, we chose to perform multiple regression analysis. This analysis allowed us to determine the degree of influence of each explanatory variable on the dependent variable "Innovation". Since each variable is measured by a large number of items, we first sought to reduce the number of items and group them into a single factor that accounts for the majority of the total information. For this we have opted for a Principal Component Analysis (PCA). This method allowed us to group the items of each variable into factors that we used later in the regression analysis.

\section{Results}

The results of the Principal Component Analysis (PCA) of the five variables are summarized in Table 6.

Table 6: PCA results

\begin{tabular}{|l|c|c|c|c|}
\hline \multicolumn{1}{|c|}{ Variables } & Number of items & Number of factors & Cumulative variance & KMO \\
\hline Innovation & 8 items & One factor & $60,08 \%$ & 0.638, Sig. 0.00 \\
\hline Internal Knowledge & 3 items & One factor & $62,77 \%$ & 0.495, Sig. 0.00 \\
\hline External Knowledge & 3 items & One factor & $54,61 \%$ & 0.557, Sig. 0.00 \\
\hline Codification & 2 items & One factor & $90,52 \%$ & 0.500, Sig. 0.00 \\
\hline Personalization & 2 items & One factor & $59,80 \%$ & 0.500, Sig. 0.00 \\
\hline
\end{tabular}

Each factor yields a significant percentage of information that allows reliable conclusions to be drawn. The internal consistency index between the items gives a meaning whose value is less than the error threshold. The quality of the sampling has produced quite reliable results. We then performed a multiple regression analysis to explain the "Innovation" variable by interacting all the explanatory variables. The analysis allows to give an idea on the quality of representation of the model and to identify the variables that exert a real influence on the variable "Innovation". Coefficients were assigned to each variable. Table 7 summarizes the results of the analysis.

Table 7: Coefficient of Determination

\begin{tabular}{|c|c|c|c|c|}
\hline Model & $\mathbf{R}$ & R Square & $\begin{array}{c}\text { Adjusted R } \\
\text { Square }\end{array}$ & $\begin{array}{c}\text { Std. Error of the } \\
\text { Estimate }\end{array}$ \\
\hline 1 & .781 & .610 & .553 & .49528656 \\
\hline
\end{tabular}


The summary table of the model gives an adjusted R-value of 55\%, this value allows us to say that the independent variables retained the variables jointly have an average explanatory power. Moreover, the table ANOVA (Table $n{ }^{\circ} 8$ ) makes it possible to see if at least one explanatory variable exerts an influence on the dependent variable. In this study, we achieved a satisfaction level of 0.00 below the error threshold (0.05). We can therefore conclude that at least one explanatory variable affects the "Innovation" variable.

Table 8: ANOVA $^{\mathrm{a}}$

\begin{tabular}{clccccc}
\hline Model & & Sum of Squares & df & Mean Square & F & Sig. \\
\hline 1 & Regression & 10.377 & 4 & 2.594 & 10.575 & $.000^{\mathrm{b}}$ \\
& Residual & 6.623 & 23 & .245 & & \\
& Total & 17.000 & 31 & & & \\
\hline
\end{tabular}

a. Dependent Variable: Innovation

b. Predictors: (Constant), Personalization, Internal Knowledge, External Knowledge, Codification

The regression results are presented in Table 9.

Table 9: Coefficients ${ }^{\mathrm{a}}$

\begin{tabular}{|c|c|c|c|c|c|}
\hline Model & \multicolumn{2}{|c|}{ Unstandardized Coefficients } & $\begin{array}{c}\text { Standardized } \\
\text { Coefficients } \\
\text { Beta } \\
\end{array}$ & $\mathbf{t}$ & Sig. \\
\hline$\overline{1(\text { Constante })}$ & $-1.000 \mathrm{E}-013$ & .088 & & .000 & 1.000 \\
\hline External Knowledge & .140 & .134 & .140 & 1.044 & .306 \\
\hline Codification & .376 & .195 & .376 & 1.928 & .064 \\
\hline Personalization & .036 & .122 & .036 & .293 & .771 \\
\hline
\end{tabular}

a. Dependent Variable: innovation

Two statistically significant influence relationships can be identified with coefficients of 0.455 and 0.376. This result suggests that the variables "Internal Knowledge" and "Codification" have a significant influence on the "Innovation" variable. On the other hand, the variables "External Knowledge" and "Personalization" give coefficients of 0.140 and 0.036 respectively with a significance of 0.306 and 0.771 respectively, which are well above the threshold of 0.05 . These two variables therefore appear to have no apparent influence on the "Innovation" variable.

\section{Discussions}

Based on the results of the statistical analysis, it can be concluded that the different knowledge management strategies, ie codification, personalization, internal knowledge management and external knowledge management, do not all have the same effects on innovation .

Indeed, in the case of artisanal enterprises surveyed, the codification strategy seems to have more impact on innovation than personalization. Hence the hypothesis 1 is confirmed. This result is quite surprising in this type of enterprise given the predominance of informal exchanges and the importance of tacit knowledge (know-how, turn of hand, intuitions). Innovation in the artisanal environment is therefore more affected by codification than by the personalization of knowledge, which corroborates the contributions of certain researches, such as, for example, Keskin [37] considering codification more significant for innovation than personalization strategy. The codification of knowledge in the artisanal enterprise takes the form of recording knowledge in working documents including registers, reports, photo albums ... these take paper or electronic form. The choice between the two forms depends on the level of integration of the new information and communication technologies, which depends on the size of the company, the profile of the manager (founding craftsman or manager) and the nature of the Artisanal activity.

The results of this research propose an integrated vision between the two strategies (codification and personalization) that cohabit in the artisanal enterprise but do not necessarily have the same level of involvement in the processes of innovation. This finding is widely shared by the literature, who believes that the codification and personalization of knowledge can improve the performance of firms differently. According to Ofek and Sarvary [51], Haas and Hansen [30], codification knowledge management saves time and can also improve coordination of effort [59]. However, the personalization strategy aims at improving product quality which is consistent with the work of Ofek and Sarvary [51], to develop skills by referring to Haas and Hansen [30] and to improve the capacity of Innovation, as suggested by Wu and Lin [59]. This is achieved through coordination and exchange between employees within a company.

Our results can also be compared with Gloet and Terziovski [26] who showed that knowledge management contributes to innovation performance when a simultaneous approach to human resource management practices (under the personalization strategy) and data management (codification strategy) is implemented. 
Moreover, the artisanal enterprise actually relies more on informal exchanges and tacit forms of knowledge than on the codification of knowledge in various forms (databases, repositories, documents, etc.). The search for a balance between strategies of codification and personalization of knowledge may be indispensable for the artisanal enterprise. It is a question of combining the two strategies by promoting exchanges and informal relationships within the company for better acquisition, assimilation and transmission of knowledge, but also by adopting codified and formal forms to transform tacit knowledge into explicit knowledge which are easier to transmit and exchange.

Concerning the contribution of internal or external knowledge to innovation, the results of the survey show a positive correlation between internal knowledge management and innovation. However, external knowledge is neutral to innovation. We conclude that only hypothesis 3 is confirmed, and hypothesis 4 is invalidated.

A reading of these results shows that internal knowledge in the artisanal enterprise is considered antecedent to innovation given their tacit nature. They are therefore difficult to imitate and exploit by competitors. On the other hand, an explicit knowledge, given its formal and codified character, can be easily acquired externally, thus losing the competitive advantage by its generalization. The artisanal business can easily have external knowledge through the adherence of customers and partners, or through the participation of employees who can filter from the outside environment knowledge useful to the company. These results confirm the work of Smith et al. (2005), but offer a contrasting view of work on the positival impact of external knowledge and absorptive capacity as an antecedent to innovation [16] and the role of open innovation which supports chesbrough's contribution to open innovation [12].

A more detailed analysis of the results on the importance of internal knowledge as an incubator of innovation makes it possible to better understand the reason for the "neutrality" of external knowledge for innovation within the artisanal enterprise. A first explanation may be related to the fact that knowledge acquired externally is not automatically integrated and appropriate by the artisanal enterprise. In other words, external knowledge can drastically change the existing knowledge or generate its total rethinking, which is why any knowledge resulting from the company's environment is subjected to a multi-phase process, in particular decoding, assimilation, Adaptation, appropriation and recodification and dissemination.

The models resulting from the work on the paradigm of open innovation, the theory of ecosystems and business models find it difficult to adapt to the artisanal enterprise for which this internal knowledge can cohabit with external knowledge, But they can not trigger innovations, otherwise the resulting innovation risks moving the company away from its core business or giving rise to products with "low cultural content".

\section{Conclusion}

This article provides relevant conclusions both for academics and for corporate managers. Our research has helped to explain the link between knowledge management strategies and innovation. The results reveal that the codification of knowledge has a positive impact on the different types of innovation in the artisanal enterprise. While the personalization of knowledge, based on the transfer of the tacit knowledge of those who master it to the people who will learn it, does not have a positive effect on innovation.

Concerning the types of knowledge that promote innovation, the study shows that it is the knowledge of internal origin that is most likely to trigger innovations in the artisanal environment, while external knowledge, despite its importance for the respondents, remain without significant effect on the ability to innovate. If our results support some theoretical and empirical researches, they are opposed to those valuing external knowledge and the strategy of personalizing knowledge in the processes of innovation. These results may possibly be explained by the specificity of the artisanal enterprise. The latter has strong roots in tradition, professional expertise, personalization and singularity of services and proximity to costumers [11]. These characteristics of the artisanal enterprise make internal knowledge a key factor for success and competitiveness because they are based on tacit knowledge that is difficult to codify and to transfer. However, in spite of these strengths, a number of weaknesses may constitute an obstacle to the innovativeness of the artisanal enterprise, in particular the weakness of its financial resources necessary to support innovation, the low rate of supervision and the predominance of family management.

In addition, our research provides managers with a fairly detailed understanding of the importance of knowledge management in the innovation process. Given the positive correlation between knowledge codification and innovation and, on the other hand, between internal knowledge and innovation, managers must first of all ensure better codification of knowledge within their companies. They must also transfer knowledge from documents or databases to employees in order to ensure better preservation and transfer of experienced craftsmen to apprentices and new recruits. Otherwise, the process of intergenerational transmission of knowledge will be dysfunctional and the original knowledge of each profession will gradually disappear. In this sense, managers must deploy the necessary means for codification (information technologies, databases, repositories) as well as the transmission and conservation of internal knowledge (training, montoring, quality 
circles, etc.). In addition, managers can use these results as an argument to convince stakeholders to implement knowledge management projects.

Finally, the main objective of this study is to provide a look at the practices of knowledge management and innovation at a given moment. This study could have been carried out according to a longitudinal approach consisting in conducting the survey periodically in order to measure the impact of certain phenomena such as, for example, the change of manager, the conclusion of a partnership on innovation and knowledge management.

The sample was obtained in six different types of artisanal enterprises, which does not allow the results to be extrapolated to other non-analyzed types such as jewelry, iron forging, basket-making, etc. In addition, an analysis of knowledge processes and their impact on different types of innovation is outside the scope of our research. We hope that the current study triggers further studies on this issue at the level of artisanal enterprises, a field of research that has not been explored, not only in Morocco but also on an international scale.

\section{Réferences}

[1] M. Alvesson and D. Kärreman, Odd couple: making sense of the curious concept of knowledge management, Journal of management studies 38 (2001), 995-1018.

[2] A. Attour and P. Barbaroux, Le rôle des processus de connaissances dans le cycle de vie d'un écosystème d'affaires, in: 6ème Rencontre du Groupe de Recherche Thématique" Innovation" de l'AIMS, 2015.

[3] A. Attour and T. Burger-Helmchen, Écosystèmes et modèles d'affaires: introduction, Revue d'économie industrielle (2014), 11-25.

[4] P. Barbaroux and A. Attour, Approches interactives de l'innovation et gestion des connaissances, Innovations (2016), 5-14.

[5] F. Bensebaa and P. Béraud, Coping with globalization: What are the driving forces of openness and spatial dynamics of innovation?, Journal of Innovation Economics \& Management (2012), 3-22.

[6] P. Bierly and A. Chakrabarti, Generic knowledge strategies in the US pharmaceutical industry, Strategic management journal 17 (1996), 123-135

[7] J.-C. Boldrini, H. Journé-Michel, and E. Chéné, L'innovation des entreprises artisanales, Revue française de gestion (2011), $25-41$.

[8] J.-C. Boldrini, H. Journé-Michel, and N. Schieb-Bienfait, Trajectoires d'innovations dans l'entreprise artisanale: une approche évolutionniste fondée sur les ressources et les compétences, in: Actes de la XVIème Conférence de l'Association Internationale de Management Stratégique (AIMS), Montréal, 6-9 Juin 2007, 2007, p. 36.

[9] N. Bontis, M.M. Crossan, and J. Hulland, Managing an organizational learning system by aligning stocks and flows, Journal of management studies 39 (2002), 437-469.

[10] S. Borghini, Organizational creativity: Breaking equilibrium and order to innovate, Journal of Knowledge Management 9 (2005), 19-33.

[11] J. Bréchet, H. Journé-Michel, and N. Schieb-Bienfait, Portrait de l'artisan en manager de projet, CIFPME (Congrès International Francophone en Entrepreneuriat et PME), Fribourg (2006).

[12] H.W. Chesbrough, Open innovation: The new imperative for creating and profiting from technology, Harvard Business Press, 2006.

[13] B. Choi and H. Lee, Knowledge management strategy and its link to knowledge creation process, Expert Systems with applications 23 (2002), 173-187.

[14] B. Choi and H. Lee, An empirical investigation of KM styles and their effect on corporate performance, Information \& Management 40 (2003), 403-417.

[15] C.W. Choo and N. Bontis, The strategic management of intellectual capital and organizational knowledge, Oxford University Press, 2002

[16] W.M. Cohen and D.A. Levinthal, Absorptive capacity: A new perspective on learning and innovation, Administrative science quarterly (1990), 128-152.

[17] R. Coombs, R. Hull, and M. Peltu, Knowledge management practices for innovation: an audit tool for improvement, CRIC, The University of Manchester CRIC Working Paper (1998).

[18] P. Corbel and G. Simoni, Innovation et partage des connaissances, Revue française de gestion (2012), 71-75.

[19] D. Doloreux and P. Bitard, Les systèmes régionaux d'innovation: discussion critique, Géographie, économie, société 7 (2005), 2136.

[20] P.F. Drucker and P.F. Drucker, Post-capitalist society, Routledge, 1994.

[21] P. Fidel, W. Schlesinger, and A. Cervera, Collaborating to innovate: Effects on customer knowledge management and performance, Journal of Business Research 68 (2015), 1426-1428.

[22] A.J. Flanagin, The elusive benefits of the technological support of knowledge management, Management Communication Quarterly 16 (2002), 242-248.

[23] B. Forés and C. Camisón, Does incremental and radical innovation performance depend on different types of knowledge accumulation capabilities and organizational size?, Journal of Business Research 69 (2016), 831-848.

[24] F. Fréry, A. Gratacap, and T. Isckia, Les écosystèmes d'affaires, par-delà la métaphore, Revue française de gestion (2012), 69-75.

[25] C. Garavelli, M. Gorgoglione, and B. Scozzi, Knowledge management strategy and organization: A perspective of analysis, Knowledge and Process Management 11 (2004), 273-282.

[26] M. Gloet and M. Terziovski, Exploring the relationship between knowledge management practices and innovation performance, Journal of Manufacturing Technology Management 15 (2004), 402-409.

[27] A. Gratacap, Les Ecosystèmes, un attracteur étrange, Management \& Avenir (2011), 100-104.

[28] P.H. Gray and D.B. Meister, Knowledge sourcing methods, Information \& Management 43 (2006), $142-156$.

[29] Z. Guo and J. Sheffield, A paradigmatic and methodological examination of knowledge management research: 2000 to 2004, Decision Support Systems 44 (2008), 673-688.

[30] M.R. Haas and M.T. Hansen, Different knowledge, different benefits: toward a productivity perspective on knowledge sharing in organizations, Strategic management journal 28 (2007), 1133-1153.

[31] M.T. Hansen and M.R. Haas, Competing for attention in knowledge markets: Electronic document dissemination in a management consulting company, Administrative science quarterly 46 (2001), 1-28.

[32] M.T. Hansen, N. Nohria, and T. Tierney, What's your strategy for managing knowledge?, The knowledge management yearbook 2000-2001 (1999), 1-10.

[33] S. Harkema, A complex adaptive perspective on learning within innovation projects, The Learning Organization 10 (2003), $340-$ 346. 
[34] A. Inuzuka and Y. Nakamori, A recommendation for IT-driven knowledge sharing, Systems and Computers in Japan 35 (2004), 111.

[35] M. Jacob, Utilization of social science knowledge in science policy: Systems of Innovation, Triple Helix and VINNOVA, Social Science Information 45 (2006), 431-462.

[36] J. Jordan and P. Jones, Assessing your company's knowledge management style, Long range planning 30 (1997), $322-398$.

[37] H. Keskin, The relationships between explicit and tacit oriented KM strategy, and firm performance, Journal of American Academy of Business 7 (2005), 169-175.

[38] R. Lema, R. Quadros, and H. Schmitz, Reorganising global value chains and building innovation capabilities in Brazil and India, Research Policy 44 (2015), 1376-1386.

[39] C. López-Nicolás and Á.L. Meroño-Cerdán, Strategic knowledge management, innovation and performance, International journal of information management 31 (2011), 502-509.

[40] A. Majchrzak, L.P. Cooper, and O.E. Neece, Knowledge reuse for innovation, Management science 50 (2004), $174-188$.

[41] A.C. Maltz, A.J. Shenhar, and R.R. Reilly, Beyond the balanced scorecard:: Refining the search for organizational success measures, Long range planning 36 (2003), 187-204.

[42] J.G. March, Exploration and exploitation in organizational learning, Organization science 2 (1991), 71-87.

[43] A. Martini and L. Pellegrini, Barriers and levers towards knowledge management configurations: A case study-based approach, Journal of Manufacturing Technology Management 16 (2005), 670-681.

[44] D. Moitra and K. Kumar, Managed socialization: How smart companies leverage global knowledge, Knowledge and Process Management 14 (2007), 148-157.

[45] T.J. Mom, F.A. Van Den Bosch, and H.W. Volberda, Investigating managers' exploration and exploitation activities: The influence of top-down, bottom-up, and horizontal knowledge inflows, Journal of management studies 44 (2007), 910-931.

[46] P.S. Mortensen and C.W. Bloch, Oslo Manual-Guidelines for collecting and interpreting innovation data, Organisation for Economic Cooporation and Development, OECD, 2005.

[47] I. Nonaka, A dynamic theory of organizational knowledge creation, Organization science 5 (1994), 14-37.

[48] I. Nonaka and G. Von Krogh, Perspective-Tacit knowledge and knowledge conversion: Controversy and advancement in organizational knowledge creation theory, Organization science 20 (2009), 635-652.

[49] I.T. Nonaka, H. 1995. The Knowledge Creating Company. How Japanese Companies Create the Dynamics of Innovation, New York (1995).

[50] E. OCDE, La mesure des activités scientifiques et technologiques, Manuel d'Oslo, Principes directeurs pour le recueil et l'interprétation des données sur l'innovation, in, Éditions OCDE, 2005.

[51] E. Ofek and M. Sarvary, Leveraging the customer base: Creating competitive advantage through knowledge management, Management science 47 (2001), 1441-1456.

[52] R.H. Robins, A short history of linguistics, Routledge, 2013

[53] J.A. Schumpeter, The theory of economic development: An inquiry into profits, capital, credit, interest, and the business cycle, Transaction publishers, 1934

[54] K.G. Smith, C.J. Collins, and K.D. Clark, Existing knowledge, knowledge creation capability, and the rate of new product introduction in high-technology firms, Academy of management journal 48 (2005), 346-357.

[55] J. Swan, S. Newell, H. Scarbrough, and D. Hislop, Knowledge management and innovation: networks and networking, Journal of Knowledge Management 3 (1999), 262-275.

[56] D.J. Teece, Strategies for managing knowledge assets: the role of firm structure and industrial context, Long range planning 33 (2000), 35-54

[57] D.J. Teece, Business models, business strategy and innovation, Long range planning 43 (2010), 172-194.

[58] J. West, A. Salter, W. Vanhaverbeke, and H. Chesbrough, Open innovation: The next decade, in, Elsevier, 2014.

[59] I.L. Wu and H.C. Lin, A strategy-based process for implementing knowledge management: An integrative view and empirical study, Journal of the American Society for Information Science and Technology 60 (2009), 789-802.

[60] M.H. Zack, Developing a knowledge strategy, California management review 41 (1999), 125-145. 